\title{
Intra-specific Variation in Virulence and In Vitro Production of Macromolecular Toxins Active Against Locust Among Beauveria bassiana Strains and Effects of In Vivo and In Vitro Passage on These factors
}

\author{
E. QUESADA-MORAGA AND A. VEY \\ Laboratoire de Recherches de Pathologie Comparée, INRA, 30380 Saint Christol \\ lez Alès, France
}

(Received 14 May 2002; returned 3 July 2002; accepted 4 November 2002)

\begin{abstract}
Strains of Beauveria bassiana isolated from locust or from the soil varied considerably in their virulence and their ability to produce in vitro toxic metabolites against Locusta migratoria. Among the pathogenic isolates, only culture filtrates of 90/2-Dm, 92/11-Dm and 0023-Su were toxic by injection, a result which demonstrates that isolates of $\mathrm{B}$. bassiana can be pathogenic for L. migratoria whether they secrete toxic metabolites in vitro or not. Toxic metabolites secreted by strains 90/2-Dm and 92/11-Dm were macromoleculer as they were retained by dialysis (cutoff of 6-8 kDa for globular proteins), whereas those secreted by 0023-Su were not. The effect o $f$ in vitro passage on virulence and on toxicogenic activity of isolate 90/2-Dm was dependent on the mycological media the inoculum was produced on. The virulence of isolate 90/2-Dm was significantly reduced after two passages through Sabouraud Dextrose Agar (SDA) whereas two passages through Malt Agar (MA) increased its virulence and its toxicogenic activity. Nevertheless, the most aggressive conidia and the most toxic macromolecules were obtained after two passages of the isolate 90/2-Dm through the host. The bioactive macromolecules present in the crude filtrate of isolate 90/2-Dm were precipitated by $90 \%$ saturation of ammonium sulphate, and the insecticidal activity was exclusively detected in high molecular mass fraction after gel filtration on Sephadex G-25. In addition, the insecticidal effect of the Sephadex G-25 fraction was significantly reduced after exposure for $2 \mathrm{~h}$ at $60^{\circ} \mathrm{C}$ and $20 \mathrm{~min}$ at $120^{\circ} \mathrm{C}$, suggesting that the insecticidal metabolites in the culture filtrates of isolate 90/2-Dm were proteinaceous.
\end{abstract}

Keywords: entomogenous fungi, Beauveria bassiana, biological control, locust, Dociostaurus maroccanus, Locusta migratoria, toxic metabolites, macromolecular toxins, bioinsecticides, insecticidal effects

Correspondence to: A. Vey, Laboratoire de Recherches de Pathologie Comparée, INRA, 30380 Saint Christol lez Alès, France. E-mail: vey@insam.inra.fr 


\section{INTRODUCTION}

The exploitation of entomopathogenic fungi for biological control of locust and grasshoppers has received much attention, especially in recent years (Prior \& Greathead, 1989; Mason \& Erlandson, 1994). That is true for the Moroccan locust Dociostaurus maroccanus (Thunberg) widely distributed in the Mediterranean area where it is an important pest (Vázquez-Lesmes \& Santiago-Álvarez, 1993). The preventive control of D. maroccanus relies on broad-spectrum synthetic insecticides (Latchininsky \& Launois-Luong, 1992). This is likely to change because some environmental issues arising from their use such as impact on operators, other people, livestock, and other arthropods, including natural enemies of this locust, have increased the demand for biological control (Lomer et al., 2001; QuesadaMoraga \& Santiago-Álvarez, 2001).

Studies on natural enemies of orthopteran insects have shown that the fungus Beauveria bassiana (Bals.) Vuill. causes epizootics in D. maroccanus populations (Hernández-Crespo \& Santiago-Álvarez, 1997), and is therefore considered, together with Bacillus thuringiensis (Berliner) (Quesada-Moraga \& Santiago-Álvarez, 2001) as a main candidate for the biological control of the Moroccan locust (Jiménez-Medina et al., 1998). Furthermore, natural isolates of this hyphomycete exhibit a high insecticidal activity when tested against D. maroccanus in laboratory assays (Jiménez-Medina et al., 1998). In field tests, the most virulent strain was more effective when applied as bait than by spraying (Jiménez-Medina et al., 1996).

Field assays with fungi have often produced inconsistent results. In addition, their slow mode of action compared with chemical insecticides has hindered commercial development (Butt et al., 2001). Therefore, to improve commercialibility of a fungus as a biological control agent, its performance must be improved in most cases. This may be achieved by incorporating more toxic modes of action to increase killing rates (St Leger et al., 1996; St Leger \& Screen, 2001). For this aim, the knowledge of the mode of action of entomopathogenic fungi is vital to develop effective commercial mycoinsecticides.

It has been shown that many entomopathogenic fungi including B. bassiana kill their hosts after only limited growth in the hemocoel, and that toxins are probably responsible for host death (Roberts, 1981). Furthermore, the penetration and development of B. bassiana in susceptible hosts involves the secretion of diverse toxic secondary metabolites. Among them are well-characterised low molecular weight insecticidal cyclic peptides (Roberts, 1981; Khachatourians, 1991; Vey et al., 2001) and poorly studied macromoleculer insecticidal metabolites, which have been directly implicated in the insecticidal properties of this hyphomycete (Mazet et al., 1994). Unfortunately, there are only a few studies on the mode of action of B. bassiana on locusts, and hardly any on the production of toxic macromolecules during infection of these hosts (Vey et al., 2001). Information is highly desirable because the selection of strains with high toxin production may eventually help identify particularly potent B. bassiana strains for the control of D. maroccanus.

For the use of entomopathogenic fungi in biological control, not only their virulence is important but also possible variations between batches of fungal propagules, and issues concerning the preservation of viability in biopreparations. More precisely, commercially available biocontrol agents have to be produced in large quantities by means of large-scale fermentation. But the continual production of inoculum on artificial media may lead to a loss of virulence of the organism (Wraight et al., 2001). In fact, throughout the literature on the entomopathogenic fungi, the effect on virulence of repeated subculturing in mycological media or passage through insect hosts has been reported by different authors (Kawakami, 1960; Schaerffenberg, 1964; Ferron et al., 1972; Fargues \& Robert, 1983; Brownbridge et al ., 2001). In contrast, no reports are available on the effect of passage of conidia through mycological media and through the host on the production of toxic metabolites by the pathogen. 
In this work, an attempt has been made to determine whether a correlation exists between the in vitro production of toxic metabolites and the pathogenicity for Locusta migratoria L. for a range of $B$. bassiana isolates. We selected $L$. migratoria as a model insect host because it is easily reared at controlled conditions. One of the fungal strains secreting toxic macromolecules in vitro was chosen for a more detailed analysis of such macromolecules and to study whether successive passages through the host and through mycological media would affect its virulence and its toxicogenic activity.

\section{MATERIAL AND METHODS}

\section{Fungi and Insects}

The strains used in this study were obtained from Dr. Cándido Santiago-Álvarez, University of Córdoba (Spain). Strains EABb 90/2-Dm, EABb 91/7-Dm, EABb 92/10-Dm and EABb 92/11-Dm were isolated from D. maroccanus (Orthoptera: Acrididae) in the breeding area of 'la Serena' in Badajoz (Spain) in 1990, 1991, 1992 and 1992, respectively. Strain EABb 91/6$\mathrm{Ci}$ was isolated from the Italian locust Calliptamus italicus $\mathrm{L}$. in the same breeding area in 1991. Finally, the soil strains EABb 00/23-Su and EABb 00/26-Su were isolated respectively from El Hierro (Canary Islands) and from 'la Serena' in 2000. Slant multispore cultures of strains were grown on Malt Agar (MA Biokar Diagnostic) at $25^{\circ} \mathrm{C}$ in the dark and then stored at $4^{\circ} \mathrm{C}$. Conidial suspensions were prepared by scraping conidia from well sporulated 21-day-old slant cultures into sterile distilled water, and estimating their concentration using a hemocytometer. Viability of conidia was checked before preparation of suspensions by germinating tests in liquid Czapek-Dox broth plus $1 \%(\mathrm{w} / \mathrm{v})$ yeast extract medium. In all the experiments, germination rates were higher than $90 \%$.

Newly emerged fourth instar L. migratoria nymphs (mean weight $361 \pm 31 \mathrm{mg}$ ) from a long established healthy colony at the Station de Recherches de Pathologic Comparée, INRA-CNRS, Saint-Christol-Lez-Alès, France, were used as a host. New locusts are regularly introduced to this colony to maintain the vigour of the insects.

\section{Experimental Infections}

To assess the pathogenicity of each strain, $8 \mu \mathrm{L}$ of a spore suspension adjusted to $1 \times 10^{5}$ conidia $\mathrm{mL}^{-1}$ were injected through the intersegmental membrane between the second and third abdominal segments, using a Desaga microinjector. Control nymphs were injected with the same volume of sterile distilled water. Dead insects were removed and placed in a humid chamber $(100 \% \mathrm{RH})$ at $30^{\circ} \mathrm{C}$ to encourage sporulation.

Batches of 10 nymphs, maintained in Plexiglas-framed cages $(12 \times 12 \times 17 \mathrm{~cm})$ with mosquito-mesh sides and roof, were placed in incubators at $28^{\circ} \mathrm{C}, 60 \%$ relative humidity and a 16:8-h L:D photoperiod. Each treatment was replicated four times with 10 nymphs/ replicate and the whole experiment was repeated. All locusts were fed fresh wheat seedlings. Nymphal mortality was recorded every $24 \mathrm{~h}$, within 10 days postinjection.

\section{Preparation of Crude Filtrates}

To prepare a primary culture, $1 \mathrm{~mL}$ of a suspension of conidia (first adjusted to $1 \times 10^{7}$ conidia $\mathrm{ml}^{-1}$ ) was inoculated into $25 \mathrm{~mL}$ of Adamek's liquid medium (40 g glucose; $40 \mathrm{~g}$ yeast extract; $30 \mathrm{~g}$ corn steep liquor (Sigma); $1000 \mathrm{~mL}$ distilled water) in a $100-\mathrm{mL}$ Erlenmeyer flask and cultured at $25^{\circ} \mathrm{C}$ on a rotatory shaker (CFL 1092) at 110 r.p.m. for 4 days. To inoculate secondary cultures for large-scale growth of the fungus, $2 \mathrm{~mL}$ of the primary culture were transferred into $250 \mathrm{~mL}$ of the same medium in a 1-L Erlenmeyer flask, and cultured under the same conditions on a TR 125 INFORS shaker for 7 days, before removing the mycelial material by filtration through filter paper (Whatman No. 3chr). 


\section{Dialysis}

One volume of unconcentrated crude filtrate was dialysed against two volumes of distilled water for $24 \mathrm{~h}$ at $4^{\circ} \mathrm{C}$. The sample was introduced in a molecular porous membrane (Spectra) with a cut-off of $6-8 \mathrm{kDa}$ for globular proteins. The adialysates were concentrated at $4^{\circ} \mathrm{C}$ by embedding the membrane in polyethylene glycol 20000 (Fluka), while the dialysates were concentrated by evaporation at room temperature in a chemistry hood. Total protein concentration was determined with the Bio-Rad Protein Assay based on the method of Bradford (1976). Bovine serum albumin was used as the standard.

\section{Passage of the Selected Strain through Mycological Media and through the Host}

To study the effect of in vitro passage through mycological media, the selected strain was sequentially subcultured by mixed conidial transfer to full-strength MA and Sabouraud Dextrose Agar (SDA, Oxoid). Each culture corresponding to a passage was incubated in the dark at $28^{\circ} \mathrm{C}$ for 3 weeks before the next subculture. Conidia were harvested from the second series of subcultures by scraping the conidia from the surface of 21 day-old cultures and suspensions were used to assess either virulence or toxin production in vitro as previously described.

To study the effect of passage through the host, $8 \mu \mathrm{L}$ of a spore suspension adjusted to $1 \times$ $10^{5}$ conidia $\mathrm{ml}^{-1}$ were injected into 20 fourth instar nymphs of $L$. migratoria. Dead insects were collected and placed under humid conditions $(100 \% \mathrm{RH})$ at $30^{\circ} \mathrm{C}$ to stimulate sporulation, and conidia sampled at the surface of sporulating cadavers were used to pass the fungus two times through the host. Finally, suspensions of conidia isolated from a sporulating cadaver of the second passage were used either to assess virulence or toxin production in vitro as previously described.

The conidia obtained from a stock slant culture, and after two passages through either MA, SDA or the host were designated $\mathrm{Cl}, \mathrm{C} 2, \mathrm{C} 3$, and $\mathrm{C} 4$, respectively. These four types of conidia were used to inoculate different cultures from which crude filtrates F1, F2, F3, and F4 were obtained, respectively. Adialysates A1, A2, A3 and A4 and dialysates D1, D2, D3, and D4 were prepared as described above by dialysis of crude filtrates F1, F2, F3, and F4, respectively.

\section{Toxicity of the Sources of Fungal Molecules}

To assess the toxicity of filtrates, adialysates and dialysates, $8 \mu \mathrm{L}$ of each solution were injected as described above, after sterilisation through a $0.2-\mu \mathrm{m}$ Dynagard filter unit. Control nymphs were injected with either sterile uninoculated broth or with fractions resulting from its dialysis. Each treatment was replicated four times, 10 nymphs each, and the whole experiment was repeated. Nymphal mortality was monitored every $24 \mathrm{~h}$, within 10 days postinjection. Observations were also made on development and feeding behaviour of the insects. Dead insects were dissected under a binocular microscope to observe the signs of activity of the injected molecules on insect tissues. Observations on the presence of any chromatic changes or morphological alterations were made on tracheae, air sacs, digestive track, fat body, muscle, cuticule and genitalia. Samples of tissues showing the signs of activity were also examined with a Nikon Microphot-FXA optic microscope. The experimental conditions of these assays were the same as described for the experimental infections.

The effect of passages through the host and through mycological media on virulence and toxin production of the selected strain was assessed and monitored following the same procedure. Filtrates F1, F2, F3 and F4, and adialysates A1, A2, A3 and A4 were injected as described above, and insects injected with either sterile uninoculated broth or with fractions resulting from its dialysis were used as controls. Each treatment was replicated four times, 10 nymphs each, and the whole experiment was repeated twice. 


\section{Precipitation of the Crude Filtrate of the Strain 90/2-Dm by Ammonium Sulphate}

Proteins from the filtrate of $90 / 2-\mathrm{Dm}$, precipitated with $90 \%$ of saturation of ammonium sulphate, were collected by centrifugation at $10000 \times g$ for $30 \mathrm{~min}$. The precipitate was desalted through a Sephadex G-25 (Pharmacia) column $(2.5 \times 30 \mathrm{~cm})$ in $50 \mathrm{mM}$ Tris $-\mathrm{HCl}$ buffer, $\mathrm{pH}$ 8.0. Then, the desalted fraction was injected to fourth instar L. migratoria nymphs as described above. Control insects were injected with $8 \mu 1$ of the Sephadex G-25 desalted fraction of the Adamek's liquid medium with the same total protein concentration. Each assay was replicated four times, 10 nymphs each, and the whole experiment repeated twice. Dead insects were dissected under a binocular microscope to observe the signs of activity of the injected molecules on insect tissues. Observations on the presence of any chromatic changes or morphological alterations were made on tracheae, air sacs, digestive track, fat body, muscle, cuticule and genitalia. Samples of tissues showing the signs of activity were also examined with a Nikon Microphot-FXA optic microscope. The experimental conditions of these assays were the same as described for the experimental infections.

\section{Temperature Effects}

Desalted fractions collected on Sephadex G-25 were incubated $2 \mathrm{~h}$ at $60^{\circ} \mathrm{C}$ and $20 \mathrm{~min}$ at $120^{\circ} \mathrm{C}$, and then injected into fourth instar L. migratoria nymphs. Control insects were injected with $8 \mu$ of the Sephadex G-25 desalted fraction of the Adamek's liquid medium with the same total protein concentration. Each assay was replicated four times, 10 nymphs each, and the whole experiment repeated.

\section{Statistical Analysis}

Mortality data were analyzed with one-way analysis of variance (ANOVA) and the least significant difference (LSD) test was used to compare means in Statistic for Windows (Anonymous, 1996). In Table 1, percentage mortality caused by crude filtrates, adialysates and dialysates has been corrected for mortality in the controls using Abbott's formula (Abbott, 1925). The cumulative mortality response across the assessment period was analysed with Kaplan-Meier survival analysis in SPSS (Statistical Package for Social Sciences in personal computers) 8.0 for Windows (SPSS, 1997). LT $_{50}$ values were calculated by mortality versus time regressions by Probit analysis. These regressions were also performed using SPSS 8.0 program.

\section{RESULTS}

Pathogenicity and in vitro Production of Metabolites Toxic for L. migratoria of B. bassiana Isolates

There was intra-specific variation in pathogenicity and in vitro secretion of toxic metabolites among the seven strains of B. bassiana tested (Table 1). All isolates were pathogenic for $L$. migratoria causing 57.5-94.4\% mortalities within 10 days, with the exception of strain 92/10$\mathrm{Dm}$, which was non-pathogenic at a dose of $8 \times 10^{2}$ conidia per insect. Significant differences were detected between strains $\left(F 7,56=282.1, P<0.001\right.$ for $8 \times 10^{2}$ conidia per insect $)$. The most virulent strains were $0023-\mathrm{Su}$ and $0026-\mathrm{Su}$ causing over $90 \%$ mortality, followed by $91 /$ 7-Dm which caused $78.8 \%$ mortality, and by the rest of strains which caused mortalities ranging between 57.5 and $61.9 \%$ (Table 1). The $\mathrm{LT}_{50}$ values of each strain infecting locusts differed significantly (confidence limits non-overlapped). The lowest $\mathrm{LT}_{50}$ value was 3.4 days for isolate $0023-\mathrm{Su}$, followed by 4.4 days for $0026-\mathrm{Su}$ and 5.4 days for $91 / 7-\mathrm{Dm}$. No significant difference was detected between $\mathrm{LT}_{50}$ values of isolates 90/2-Dm (6.8 days), 91/6$\mathrm{Ci}$ (6.9 days) and 92/11-Dm (7.1 days).

There were also significant differences between isolates in toxicity of crude filtrates $\left(F_{7,56}=170.11, P<0.001\right.$ for $4.8 \mu \mathrm{g}$ of total protein/insect $)$ and adialysates $\left(F_{7,56}=196.72\right.$, 
TABLE 1. Susceptibility of fourth instar nymphs of L. migratoria to different strains of $B$. bassiana and to different sources prepared from their cultures in Adamek's liquid medium. Nymphs inoculated respectively by injection of $8 \times 10^{2}$ conidia per insect, $8 \mu \mathrm{L}$ of crude filtrates at a dose of $600 \mu \mathrm{g}$ of total protein ml, $8 \mu \mathrm{L}$ of adialysates at a dose of $900 \mu \mathrm{g}$ of total protein of $\mathrm{ml}$ and $8 \mu \mathrm{l}$ of dialysates. Four replicates with 10 nymphs/replicate and whole experiment repeated two times

\begin{tabular}{|c|c|c|c|c|c|c|c|c|}
\hline & \multicolumn{2}{|c|}{ Conidia } & \multicolumn{2}{|c|}{ Crude filtrate } & \multicolumn{2}{|c|}{ Adialysatet } & \multicolumn{2}{|c|}{ Dialysate } \\
\hline & $\begin{array}{c}\text { Mean } \\
\text { mortality } \\
(\% \pm \text { SD })^{*}\end{array}$ & $\begin{array}{l}\mathrm{LT}_{50}(95 \% \\
\text { conf int)** }\end{array}$ & $\begin{array}{c}\text { Mean } \\
\text { mortality } \\
(\% \pm S D)\end{array}$ & $\begin{array}{c}\mathrm{LT}_{50}(95 \% \\
\text { conf int })\end{array}$ & $\begin{array}{c}\text { Mean } \\
\text { mortality } \\
(\% \pm S D)\end{array}$ & $\begin{array}{c}\mathrm{LT}_{50}(95 \% \\
\text { conf int })\end{array}$ & $\begin{array}{c}\text { Mean } \\
\text { mortality } \\
(\% \pm \mathrm{SD})\end{array}$ & $\begin{array}{c}\mathrm{LT}_{50}(95 \% \\
\text { conf int })\end{array}$ \\
\hline EABb 90/2-Dm & $57.5 \pm 9.3 \mathrm{a}$ & $6.8(5.9-7.9)$ & $56.3 \pm 4.4 \mathrm{a}$ & $8.0(7.4-8.8)$ & $60.0 \pm 7.5 \mathrm{a}$ & $6.1(5.2-6.9)$ & $4.2 \pm 1.8 \mathrm{a}$ & DA \\
\hline EABb 91/6-Ci & $61.3 \pm 5.8 \mathrm{a}$ & $6.9(6.0-8.1)$ & $14.4 \pm 3.2 \mathrm{~b}$ & DA & $8.1 \pm 2.5 \mathrm{~b}$ & DA & $5.6 \pm 3.2 \mathrm{a}$ & DA \\
\hline EABb 91/7-Dm & $78.8 \pm 6.9 \mathrm{~b}$ & $5.4(4.6-6.2)$ & $11.3 \pm 3.5 \mathrm{bc}$ & $\mathrm{DA}$ & $8.8 \pm 4.3 \mathrm{~b}$ & DA & $6.3 \pm 2.3 \mathrm{a}$ & DA \\
\hline EABb $92 / 10-\mathrm{Dm}$ & $0.0 \mathrm{c}^{-}$ & DA & $11.3 \pm 2.3 \mathrm{bc}$ & DA & $11.2 \pm 3.5 \mathrm{~b}$ & DA & $5.0 \pm 2.6 \mathrm{a}$ & DA \\
\hline EABb 92/11-Dm & $61.9 \pm 5.9 \mathrm{a}$ & $7.0(6.2-8.1)$ & $48.8 \pm 6.9 \mathrm{~d}$ & $\mathrm{DA}$ & $52.5 \pm 5.9 \mathrm{c}$ & $7.2(6.4-8.1)$ & $4.3 \pm 1.7 \mathrm{a}$ & DA \\
\hline EABb 0023-Su & $94.4 \pm 4.9 \mathrm{~d}$ & $3.4(2.8-4.4)$ & $35.0 \pm 5.3 \mathrm{e}$ & DA & $10.0 \pm 2.6 \mathrm{~b}$ & DA & $10.6 \pm 4.9 \mathrm{~b}$ & DA \\
\hline EABb 0026-Su & $90.0 \pm 7.5 \mathrm{~d}$ & $4.3(3.8-5.0)$ & $10.6 \pm 3.2 \mathrm{bc}$ & DA & $12.5 \pm 1.5 \mathrm{~b}$ & DA & $5.0 \pm 3.8 \mathrm{a}$ & DA \\
\hline Control & $5.6 \pm 1.7 \mathrm{e}$ & DA & $7.5 \pm 2.6 \mathrm{c}$ & $\mathrm{DA}$ & $6.8 \pm 2.5 \mathrm{~b}$ & DA & $4.5 \pm 2.8 \mathrm{a}$ & DA \\
\hline
\end{tabular}

*Mortality by injection after 10 days post injection. Means within columns with the same letter are not significantly different (least significant difference $P>0.05$ ) Mortality caused by crude filtrates, adialysates and dialysates corrected using Abbott's formula

$* * \mathrm{LT}_{50}$ times in days when $50 \%$ of nymphs were dead.

DA, insects were not killed and ultimately developed into healthy adults. 
$P<0.001$ for $7.2 \mu \mathrm{g}$ of total protein/insect). Significant insecticidal activity was only detected when nymphs were injected with crude filtrates of isolates 90/2-Dm, 92/11-Dm, 0023Su and 91/6-Ci (Table 1). Crude filtrate of 90/2-Dm was the most toxic one, causing $56.3 \%$ mortality, followed by $92 / 11-\mathrm{Dm}$, causing $48.8 \%$ mortality and by $0023-\mathrm{Su}$, with caused $35.0 \%$ mortality. Mortality caused by crude filtrate of $91 / 6-\mathrm{Ci}$ was also slightly higher than controls (Table 1). In contrast to crude filtrates, significant insecticidal activity was only detected when nymphs were injected with adialysates of isolates 90/2-Dm and 92/11-Dm, adialysates of strains $0023-\mathrm{Su}$ and $91 / 6-\mathrm{Ci}$ being non-toxic (Table 1). The adialysate of isolate 90/2-Dm was the most toxic one, causing 60\% mortality, followed by adialysate of $92 / 11-\mathrm{Dm}$, which caused $52.5 \%$ mortality. The adialysate of isolate $90 / 2-\mathrm{Dm}$ had a $\mathrm{LT}_{50}$ of 6.1 days, which was significantly lower than that of 7.2 days of isolate $92 / 11-\mathrm{Dm}$ (Table 1). Injection of dialysates of each strain caused no significant mortality, with the exception of isolate 0023 $\mathrm{Su}$, which caused a weak, however significant mortality of $10.6 \%$.

\section{Effect of Passage through Mycological Media and Through the Host on Virulence and Secretion of Toxic Metabolites of Strain 90/2-Dm}

The effect of the in vitro passage of the strain 90/2-Dm on its virulence was dependent on the mycological media the inoculum was produced on. Significant differences were detected between average survival time (AST) of controls and of insects injected with conidia $\mathrm{Cl}, \mathrm{C} 2$ and $\mathrm{C} 3$ at a dose of $8 \times 10^{2}$ conidia/insect (Table 2a,b). The lowest AST was 7.3 days for nymphs injected with conidia $\mathrm{C} 2$, followed by 8.4 days for $\mathrm{C} 1$ and 8.9 days for $\mathrm{C} 3$ (Table $2 \mathrm{a}, \mathrm{b})$. The in vivo passage of the isolate 90/2-Dm led to the most virulent conidia (C4), which had significantly lower AST than conidia $\mathrm{C} 2, \mathrm{C} 1$ and $\mathrm{C} 3$ and gave a value of 6.2 days (Table $2 \mathrm{a}, \mathrm{b})$. The mortality rates observed for conidia C1, C2, C3 and C4, were 46.25, 72.5, 27.5 and $80 \%$, respectively (Figure 1).

The passage in vitro and in vivo of the strain 90/2-Dm also affected its toxicogenic activity. Table $3 \mathrm{a}$, b shows the AST of controls and of locusts injected with $8 \mu \mathrm{l}$ of crude filtrates $\mathrm{Fl}$, F2, F3, and F4 at a dose of $500 \mu \mathrm{g} \mathrm{mL}^{-1}$ of total protein. Nymphs injected with the four types of filtrates showed AST significantly lower than the one of controls, whereas no significant differences were observed between the diverse crude filtrates (Table 3a,b). The highest and lowest values of mortality were $37.5 \%$ (F3) and 55\% (F4), respectively (Figure 2).

Table 4a,b summarizes the AST of controls and locust injected with $8 \mu \mathrm{L}$ of adialysates $\mathrm{A} 1, \mathrm{~A} 2, \mathrm{~A} 3$, and A4, at a concentration of $800 \mu \mathrm{g} \mathrm{mL}-1$ of total protein. Injection of the four types of sources of macromolecules significantly reduced the AST of nymphs as compared to controls (Table 4a,b). Significant differences were also detected between the four types of adialysates. The lowest AST observed for nymphs injected with adialysate A4 was 5.5 days, followed by A2 (6.2 days), A3 (7.6 days), and A1 (8.3 days). Mortality rates observed for adialysates A1, A2, A3, and A4 were 37.5, 70, 55 and 72.5\%, respectively (Figure 3). Dialysates D1, D2, D3, and D4 were not toxic to fourth instar nymphs of $L$. migratoria .

L. migratoria nymphs injected with crude filtrates or adialysates of isolate 90/2-Dm showed signs of weakness as early as 3 days after treatment, and they fed and developed at lower rates than the controls. Furthermore, most of the nymphs injected with the crude filtrates and adialysates remained at fourth instar, whereas most of the controls reached the fifth instar, although these data were not quantified. Observation of tissues of cadavers under binocular and light microscopes revealed melanized dark spots on tracheae, air sacs, and melanized nodules in the fat body in contact with the cuticle (Figure 4).

\section{Insecticidal activity of the proteins from the crude filtrate of 90/2-Dm precipitated with ammonium sulphate}

The AST of nymphs injected with $8 \mu \mathrm{L}$ of the Sephadex G-25 fraction of 90/2-Dm at a dose of $1 \mathrm{mg} \mathrm{mL}{ }^{-1}$ was 4.1 days, which was significantly lower $(\log$ rank $=306.94 ; P<0.0001)$ 
TABLE 2. Susceptibility of fourth instar nymphs of L. migratoria to conidia of the strain 90/2-Dm of B. bassiana from a stock culture or collected after different passages. Nymphs inoculated by injection of $8 \times 10^{2}$ conidia per insect. Four replicates with 10 nymphs/replicate; whole experiment repeated two times

\begin{tabular}{|c|c|c|c|c|c|}
\hline & Control & $\mathrm{C} 1 *$ & $\mathrm{C} 2$ & $\mathrm{C} 3$ & $\mathrm{C} 4$ \\
\hline \multicolumn{6}{|c|}{ (a) Kaplan-Meier analysis of average survival time (AST) in days } \\
\hline AST $( \pm$ SE $)$ & $9.53( \pm 0.18)$ & $8.38( \pm 0.24)$ & $7.30( \pm 0.22)$ & $8.90( \pm 0.23)$ & $6.20( \pm 0.22)$ \\
\hline $95 \%$ Conf. Int. & $9.17,9.88$ & $7.91,8.84$ & $6.88,7.72$ & $8.46,9.34$ & $5.76,6.63$ \\
\hline \multicolumn{6}{|c|}{ (b) Log rank statistic and significance of survival times between treatments ( $P \leq 0.05$ indicates significant difference) } \\
\hline & Control & $\mathrm{C} 1$ & $\mathrm{C} 2$ & $\mathrm{C} 3$ & \\
\hline $\mathrm{Cl}$ & $\begin{array}{l}26.39 \\
P<0.0001\end{array}$ & & & & \\
\hline $\mathrm{C} 2$ & $\begin{array}{l}63.77 \\
P<0.0001\end{array}$ & $\begin{array}{l}11.77 \\
P=0.0006\end{array}$ & & & \\
\hline $\mathrm{C} 3$ & $\begin{array}{l}8.90 \\
P=0.0029\end{array}$ & $\begin{array}{l}5.35 \\
P=0.0208\end{array}$ & $\begin{array}{l}30.65 \\
P<0.0001\end{array}$ & & \\
\hline $\mathrm{C} 4$ & $\begin{array}{l}81.50 \\
P<0.0001\end{array}$ & $\begin{array}{l}28.30 \\
P<0.0001\end{array}$ & $\begin{array}{l}10.01 \\
P=0.0016\end{array}$ & $\begin{array}{l}50.06 \\
P<0.0001\end{array}$ & \\
\hline
\end{tabular}

*The conidia designtated $\mathrm{C} 1, \mathrm{C} 2, \mathrm{C} 3$, and $\mathrm{C} 4$ were obtained from a stock slant culture, after two passages through MA, after two passages through SDA and after two passages through the host, respectively. 


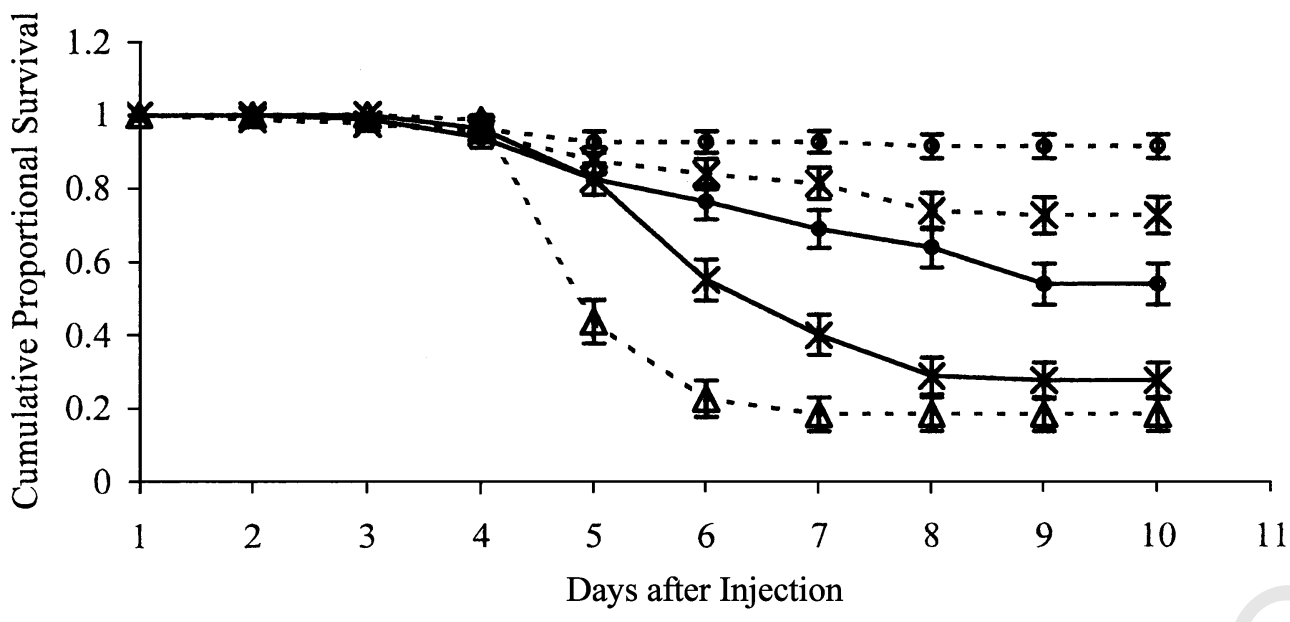

FIGURE 1. Cumulative proportional survival of fourth instar L. migratoria nymphs injected with conidia of strain 90/2-Dm of $B$. bassiana after passage through different culture media. Conidia $\mathrm{C} 1$ were obtained from a stock slant culture (solid line and $\bigcirc$ ), $\mathrm{C} 2$ after two passages through MA (solid line and $\times$ ), C3 after two passages through SDA (dashed line and $\times$ ), and C4 after two passages through the host (dashed line and $\Delta$ ). In all treatments the dose was $8 \times 10^{2}$ conidia per insect. Control insects were injected with $8 \mu \mathrm{L}$ of sterile distilled water (dashed line and $\bigcirc$ ). Data are mean $\pm \mathrm{SE}$.

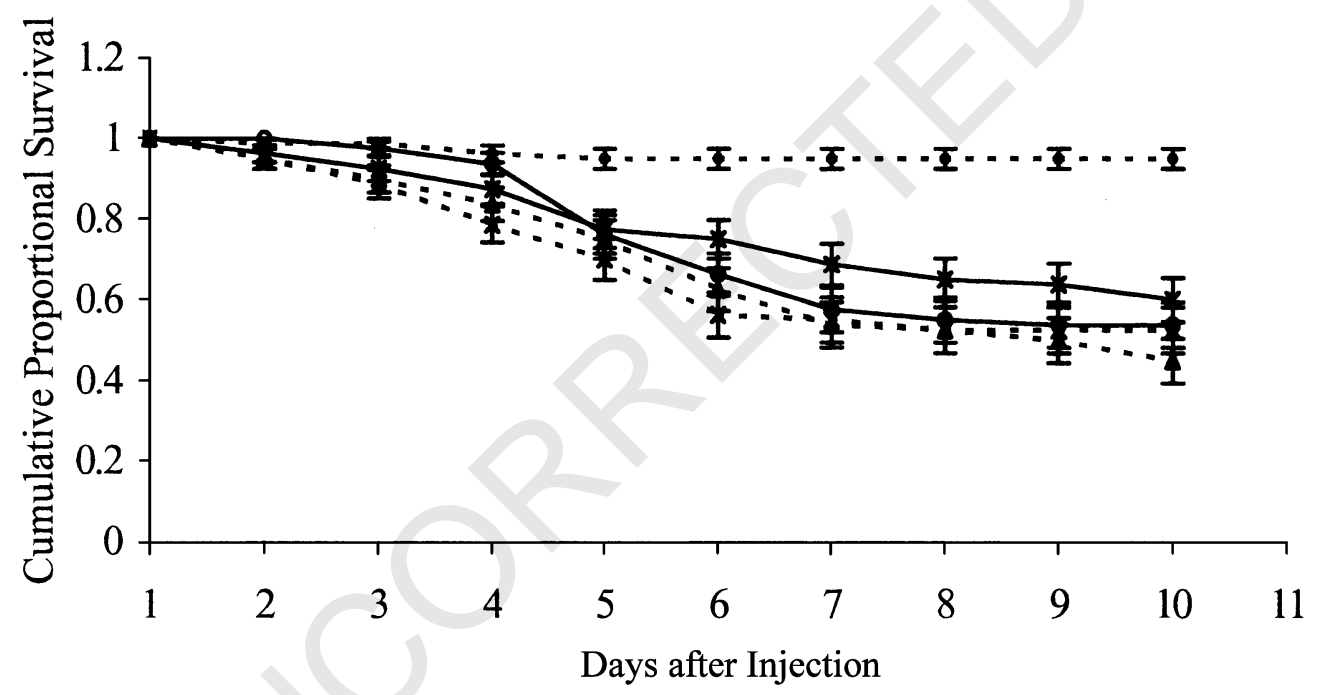

FIGURE 2. Cumulative proportional survival of fourth instar L. migratoria nymphs injected with $8 \mu \mathrm{L}$ of different crude filtrates of strain 90/2-Dm. Crude filtrate F1 was obtained from conidia C1 (solid line and $\bigcirc$ ), F2 from conidia C2 (solid line and $\times$ ), F3 from conidia C3 (dashed line and $\times$ ), and F4 from conidia C4 (dashed line and $\Delta$ ). Control insects were injected with $8 \mu \mathrm{L}$ of sterile Adamek's liquid medium (dashed line and $\bigcirc$ ). The concentration of total proteins of the filtrates was $500 \mu \mathrm{g} \mathrm{mL}^{-1}$. Data are mean $\pm \mathrm{SE}$.

than that of 9.6 days, observed for the controls. The Sephadex G-25 fraction was highly toxic causing a $98.7 \%$ mortality within 10 days insects injected with the G-25 desalted fraction 
TABLE 3. Susceptibility of fourth instar nymphs of L. migratoria to different crude filtrates of cultures of isolate 90/2-Dm. Nymphs inoculated by injection of $8 \mu$ l of solution at a concentration of total protein of $500 \mu \mathrm{g} \mathrm{mL}^{-1}$. Four replicates with 10 nymphs/replicate; whole experiment repeated two times

\begin{tabular}{|c|c|c|c|c|c|}
\hline & Control & $\mathrm{Fl}^{*}$ & $\mathrm{~F} 2$ & F3 & $\mathrm{F} 4$ \\
\hline \multicolumn{6}{|c|}{ (a) Kaplan-Meier analysis of average survival time (AST) in days } \\
\hline AST $( \pm$ SE $)$ & $9.69( \pm 0.15)$ & $8.00( \pm 0.26)$ & $8.26( \pm 0.29)$ & $7.49( \pm 0.32)$ & $7.63( \pm 0.31)$ \\
\hline $95 \%$ Conf. Int. & $9.38,9.99$ & $7.49,8.51$ & $7.69,8.84$ & $6.86,8.11$ & $7.03,8.22$ \\
\hline \multicolumn{6}{|c|}{ (b) Log rank statistic and significance of survival times between treatments ( $P \leq 0.05$ indicates significant difference) } \\
\hline & Control & $\mathrm{F} 1$ & F2 & F3 & \\
\hline $\mathrm{F} 1$ & $\begin{array}{l}34.10 \\
P<0.0001\end{array}$ & & & & \\
\hline $\mathrm{F} 2$ & $\begin{array}{l}27.26 \\
P<0.0001\end{array}$ & $\begin{array}{l}0.51 \\
P=0.4763\end{array}$ & & & \\
\hline F3 & $\begin{array}{l}36.49 \\
P<0.0001\end{array}$ & $\begin{array}{l}0.39 \\
P=0.5331\end{array}$ & $\begin{array}{l}1.41 \\
P=0.2345\end{array}$ & & \\
\hline $\mathrm{F} 4$ & $\begin{array}{l}46.44 \\
P<0.0001\end{array}$ & $\begin{array}{l}1.25 \\
P=0.2636\end{array}$ & $\begin{array}{l}3.40 \\
P=0.0653\end{array}$ & $\begin{array}{l}0.27 \\
P=0.6040\end{array}$ & \\
\hline
\end{tabular}

*The Crude Filtrates designated F1, F2, F3, and F4 were obtained from cultures inoculated respectively with conidia C1, C2, C3, and C4 of the strain 90/2-Dm of $B$. bassiana. 
TABLE 4. Susceptibility of fourth instar nymphs of $L$. migratoria to different adialysates of culturc of isolate 90/2-Dm of $B$. bassiana. Nymphs inoculated by injection of 8 $\mu \mathrm{L}$ at a concentration of total protein of $800 \mu \mathrm{g} \mathrm{m}{ }^{-1}$. Four replicates with 10 nymphs/replicate; whole experiment repeated two times

\begin{tabular}{|c|c|c|c|c|c|}
\hline & Control & $\mathrm{Al} 1^{*}$ & A2 & A3 & A4 \\
\hline $\begin{array}{l}\text { (a) Kaplan-Me } \\
\text { AST ( } \pm \text { SE) } \\
95 \% \text { Conf. Int. }\end{array}$ & $\begin{array}{l}\text { average surviv } \\
9.68( \pm 0.16) \\
9.36,9.99\end{array}$ & $\begin{array}{l}\text { in days } \\
8.29( \pm 0.27) \\
7.75,8.83\end{array}$ & $\begin{array}{l}6.25( \pm 0.30) \\
5.66,6.84\end{array}$ & $\begin{array}{l}7.63( \pm 0.30) \\
7.03,8.22\end{array}$ & $\begin{array}{l}5.53( \pm 0.32) \\
4.90,6.15\end{array}$ \\
\hline \multicolumn{5}{|c|}{ (b) Log rank statistic and significance of survival times between treatments ( $P \leq 0.05$ indicates significant difference) } & \\
\hline A1 & $\begin{array}{l}25.61 \\
P<0.0001\end{array}$ & & & & \\
\hline A2 & $\begin{array}{l}79.97 \\
P<0.0001\end{array}$ & $\begin{array}{l}23.19 \\
P<0.0001\end{array}$ & & & \\
\hline A3 & $\begin{array}{l}44.64 \\
P<0.0001\end{array}$ & $\begin{array}{l}3.58 \\
P=0.0586\end{array}$ & $\begin{array}{l}9.24 \\
P=0.0024\end{array}$ & & \\
\hline A4 & $\begin{array}{l}86.57 \\
P<0.0001\end{array}$ & $\begin{array}{l}31.76 \\
P<0.0001\end{array}$ & $\begin{array}{l}1.70 \\
P=0.1927\end{array}$ & $\begin{array}{l}15.82 \\
P=0.0001\end{array}$ & \\
\hline
\end{tabular}

*The adialysates A1, A2, A3 and A4 were obtained by dialysis of crude filtrates F1, F2, F3, and F4, respectively. 


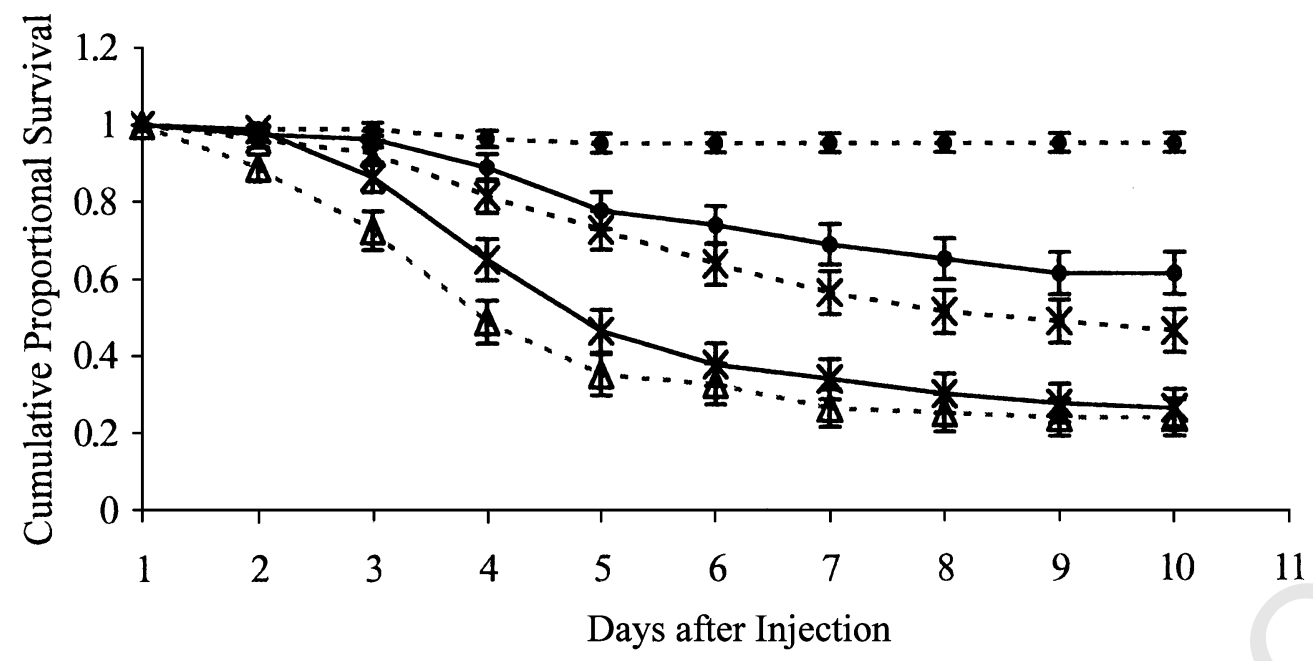

FIGURE 3. Cumulative proportional survival of fourth instar L. migratoria nymphs injected with $8 \mu \mathrm{L}$ of different adialysates of strain 90/2-Dm. Adialysate A1 was obtained from crude filtrate F1 (solid line and $\bigcirc$ ), A2 from crude filtrate F2 (solid line and $\times$ ), A3 from crude filtrate F3 (dashed line and $\times$ ), and $\mathrm{A} 4$ from crude filtrate $\mathrm{C} 4$ (dashed line and $\Delta$ ). Control insects were injected with $8 \mu \mathrm{L}$ of sterile adialysate of Adamek's liquid medium (dashed line and $\bigcirc$ ). The concentration of total protein of the adialysates was $808 \mu \mathrm{g} \mathrm{mL}^{-1}$. Data are mean $\pm \mathrm{SE}$.

showed the same symptoms when they were injected with crude filtrates and adialysates (Figure 4). In addition, a paralysis, characterised by an inability of the insect to right itself when placed on its dorsum was also observed.

The toxicity of the Sephadex G-25 fraction of the crude filtrate of isolate 90/2-Dm was significantly reduced by the two treatments at 60 and $120^{\circ} \mathrm{C}$ (Table 5). The untreated Sephadex G-25 traction had significantly lower AST (4.5 days) than when it was incubated 2 $\mathrm{h}$ at $60^{\circ} \mathrm{C}$ (7.7 days) and $20 \mathrm{~min}$ at $120^{\circ} \mathrm{C}$ (8.6 days), whereas no significant differences were observed between the two heat treatments. In addition, the Sephadex G-25 fraction caused over $95 \%$ mortality, which was significantly higher than the values of mortality observed for the same fraction after incubation $2 \mathrm{~h}$ at $60^{\circ} \mathrm{C}(50 \%)$ and $20 \mathrm{~min}$ at $120^{\circ} \mathrm{C}\left(35^{\circ} \%\right)$ (Figure 5).

\section{DISCUSSION}

Research on toxic metabolites from our collection of isolates of B. bassiana is motivated by the importance of the analysis of their role in fungal pathogenesis. The selection of a fungal strain producing toxic metabolites that are implicated in its mode of action awaits the application of molecular techniques to improve its virulence and to develop an effective commercial mycoinsecticide (St Leger \& Screen, 2001). An additional aim from an applied point of view, is the evaluation of the potential of these toxic fungal compounds as new bioinsecticides.

Isolates of B. bassiana varied considerably in their virulence and their ability to produce toxic metabolites in vitro. As our main objective was to examine the correlation between pathogenicity of a given isolate and its ability to produce toxic metabolites in vitro, all the bioassays were conducted by intrahaemocoelic injection, this method being the only valid one for such an approach (Roberts, 1981). This work shows that even under these experimental conditions, mortality rates can vary. Soil strains 0023-Su and 0026-Su were the most virulent, whereas strains isolated from D. maroccanus and C. italicus were moderately virulent. Surprisingly, isolates $902-\mathrm{Dm}$ and $91 / 6-\mathrm{Ci}$ are much more aggressive 

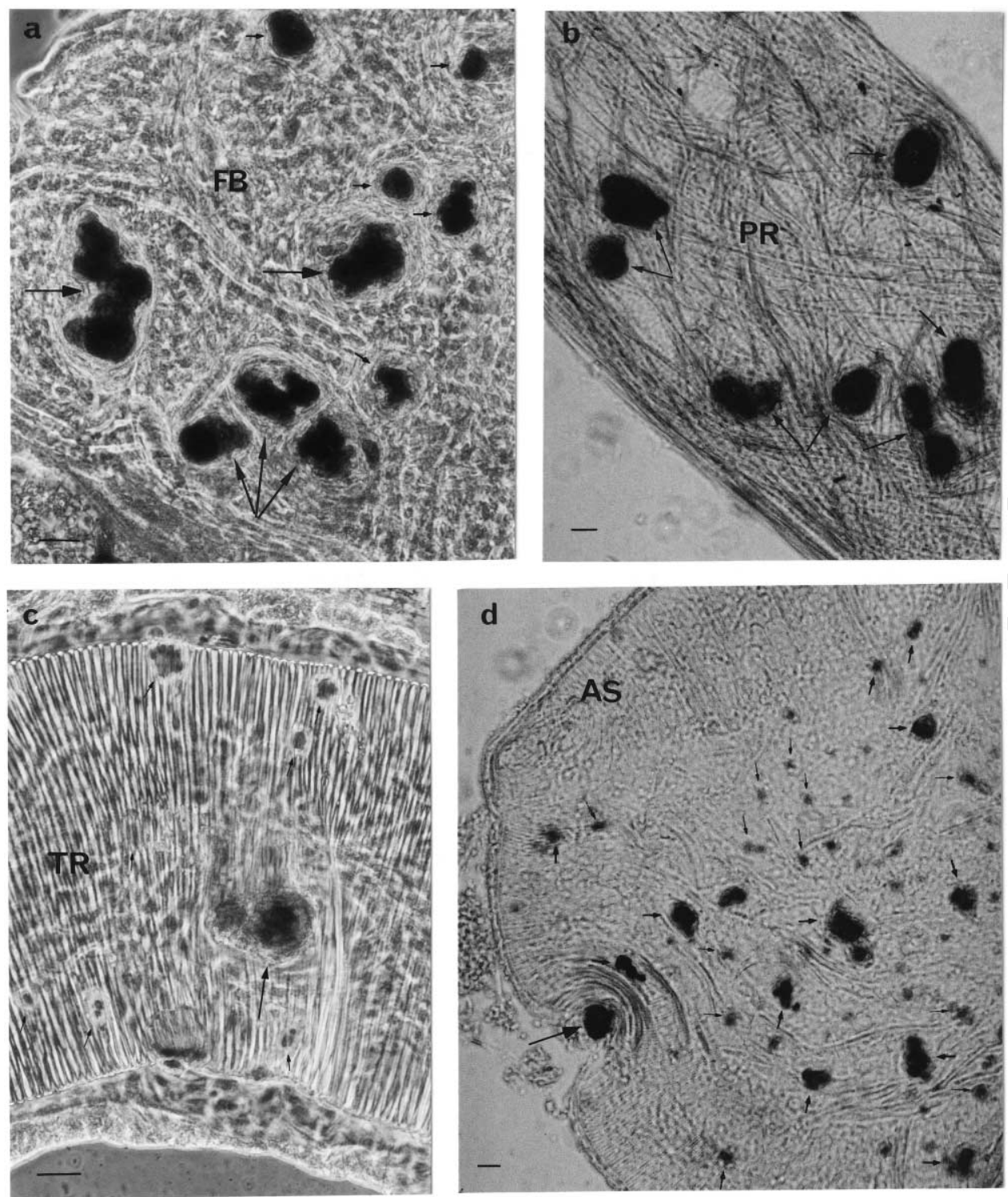

FIGURE 4. Effects of injection of different sources of toxic metabolites secreted in vitro by strain 90/2-Dm on different tissues of fourth instar nymphs of L. migratoria. (a) Melanized nodules (arrows) in the fat body (FB) induced by injection of $8 \mu \mathrm{L}$ of crude filtrate $\mathrm{F} 4$ at a dose of $500 \mu \mathrm{g} \mathrm{mL}^{-1} 3$ days post-treatment (bar:20 $\mu \mathrm{m}$ ). (b) Melanized dark spots (arrows) on the proctodeum (PR) induced by injection of $8 \mu \mathrm{L}$ of adialysate $\mathrm{A} 4$ at a dose of $800 \mu \mathrm{g} \mathrm{mL} \mathrm{m}^{-1} 4$ days post-treatment (bar: $2 \mu \mathrm{m}$ ). (c) Melanized dark spots (arrows) on trachea (TR) induced by injection of $8 \mu \mathrm{L}$ of adialysate $\mathrm{A} 2$ at a dose of $800 \mu \mathrm{g} \mathrm{mL}^{-1} 4$ days post-treatment (bar: $20 \mu \mathrm{m}$ ). (d) Melanized dark spots (arrows) on an air sac (AS) induced by injection of $8 \mu \mathrm{L}$ of the Sephadex G-25 desalted fraction at a dose of $1 \mathrm{mg} \mathrm{mL}^{-1} 4$ days post-treatment (bar: $20 \mu \mathrm{m}$ ).

against D. maroccanus by contact exposure (Jiménez-Medina et al., 1998) than isolate 0023$\mathrm{Su}$ (Santiago-Álvarez, unpublished data), which is only weakly pathogenic to the Moroccan locust, causing less than $20 \%$ mortality. Similar differences in virulence between contact and 
TABLE 5. Effect of heat treatments on the insecticidal activity of the Sephadex G-25 fraction of strain 90/2Dm against fourth instar nymphs of L. migratoria

\begin{tabular}{|c|c|c|c|c|}
\hline & Control & G-25* & $\mathrm{G}-25\left(2 \mathrm{~h}\right.$ at $\left.60^{\circ} \mathrm{C}\right)$ & $\mathrm{G}-25\left(20 \mathrm{~min}\right.$ at $\left.120^{\circ} \mathrm{C}\right)$ \\
\hline $\begin{array}{l}\text { (a) Kaplan-Meier and } \\
\text { AST ( } \pm \text { SE) } \\
95 \% \text { Conf. Int. }\end{array}$ & $\begin{array}{l}\text { sis of average } \\
10( \pm 0.0)\end{array}$ & $\begin{array}{l}\text { arvival time }(\mathrm{A} \\
4.50( \pm 0.36) \\
3.80,5.20\end{array}$ & $\begin{array}{l}\text { in days } \\
7.65( \pm 0.57) \\
6.54,8.76\end{array}$ & $\begin{array}{l}8.55( \pm 0.33) \\
7.62,9.48\end{array}$ \\
\hline \multicolumn{5}{|c|}{$\begin{array}{l}\text { (b) Log Rank statistic and significance of survival times between treatments }(P \leq 0.05 \text { indicates significan } \\
\text { difference) }\end{array}$} \\
\hline G-25 & $\begin{array}{l}38.61 \\
P<0.0001\end{array}$ & & & \\
\hline $\mathrm{G}-25\left(2 \mathrm{~h} 60^{\circ} \mathrm{C}\right)$ & $\begin{array}{l}13.17 \\
P=0.0003\end{array}$ & $\begin{array}{l}15.40 \\
P<0.0001\end{array}$ & & \\
\hline $\mathrm{G}-25\left(20 \min 120^{\circ} \mathrm{C}\right)$ & $\begin{array}{l}8.27 \\
P=0.0040\end{array}$ & $\begin{array}{l}24.18 \\
P<0.0001\end{array}$ & $\begin{array}{l}1.21 \\
P=0.2718^{8}\end{array}$ & \\
\hline
\end{tabular}

*The concentration of total proteins of the Sephadex G-25 fraction of isolate 90/2-Dm was $1 \mathrm{mg} \mathrm{mL}^{-1}$.

injection treatments have been also reported by Amiri-Besheli et al. (2000), suggesting the importance of the cuticle as a barrier to fungal infections.

Our results suggest that isolates of $B$. bassiana can be pathogenic for $L$. migratoria whether they have the ability to produce toxic metabolites in vitro or not. Among pathogenic isolates, only 90/2-Dm and 92/11-Dm secreted in vitro macromolecules toxic for $L$. migratoria, retained by dialysis with a membrane with a cut-off of $6-8 \mathrm{kDa}$ for globular proteins. The crude filtrate of isolate $0023-\mathrm{Su}$ was slightly toxic, whereas the adialysate was

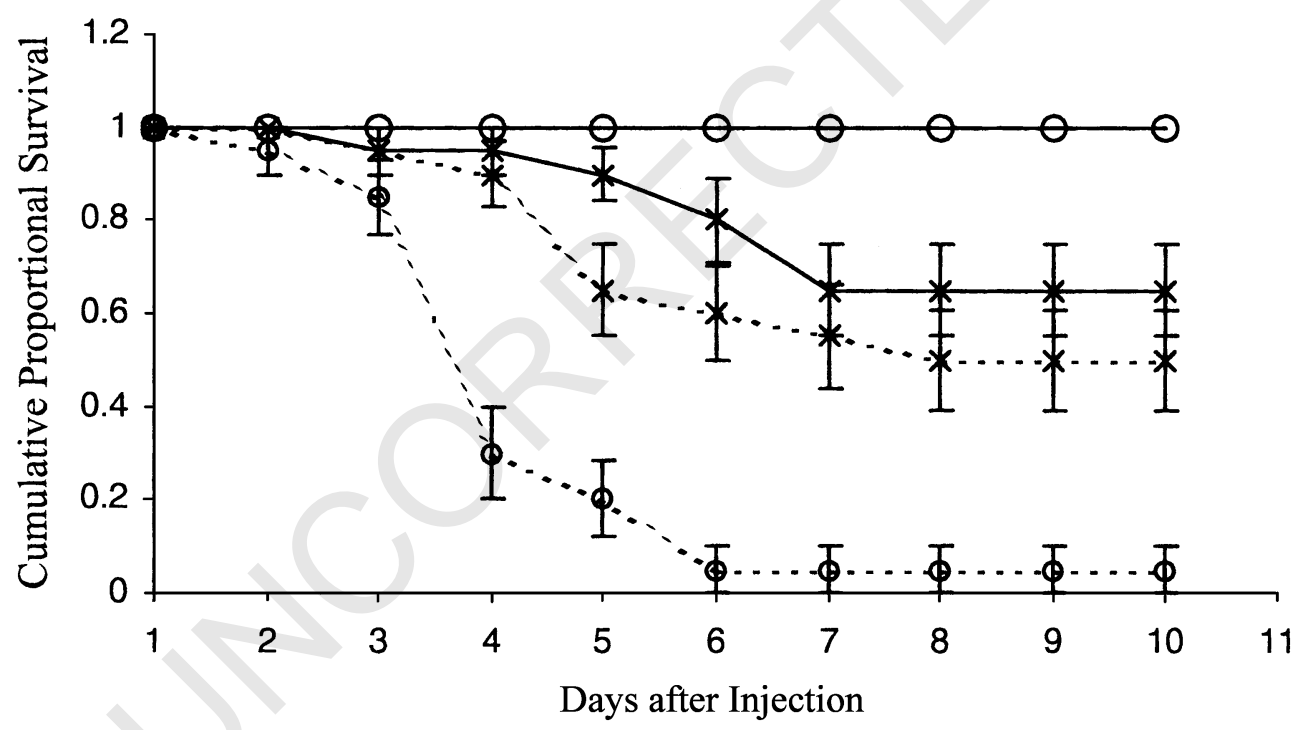

FIGURE 5. Cumulative proportional survival of fourth instar L. migratoria nymphs injected with $8 \mu \mathrm{L}$ of the Sephadex G-25 desalted fraction of strain 90/2-Dm of B. bassiana (dashed line and $\bigcirc$ ), with the same fraction incubated $2 \mathrm{~h}$ at $60^{\circ} \mathrm{C}$ (dashed line and $\times$ ) and $20 \mathrm{~min}$ at $120^{\circ} \mathrm{C}$ (solid line and $\times)$. The total protein concentration was $1 \mathrm{mg} \mathrm{mL}^{-1}$ in the three treatments. Control insects were injected with $8 \mu \mathrm{L}$ of the Sephadex G-25 desalted fraction of the Adamek's liquid medium with the same total protein concentration (solid line and $\bigcirc$ ). Data are mean $\pm \mathrm{SE}$. 
not. As the dialysate of this strain was the only one to show certain toxicity, an extraction of the crude filtrate with a conventional organic solvent used to extract small secondary metabolites would confirm if molecules such as cyclic peptides were responsible for this toxic activity.

Similarities can be noted between our data and the intra-specific variations already observed in the production of insecticidal cyclodepsipeptides of the group of destruxins by strains of M. anisopliae (Kershaw et al., 1999; Amiri-Besheli et al., 2000). Even if the majority of virulent strains of this fungal pathogen produce large quantities of destruxins, low mycotoxin producers may also be virulent, and exceptionally highly virulent strains may produce no destruxins in vitro. The strains that grow abundantly as hyphal elements in the haemolymph and do not cause destruxin-induced paralysis are considered by Kershaw et al. (1999) as representative of the 'growth strategy'. In contrast, the destruxin producing strains of $M$. anisopliae, as well as isolates 90/2-Dm, 92/11-Dm and 0023-Su of B. bassiana, could follow a 'toxin strategy'. However, the case of strains 90/2-Dm and 92/11-Dm is original, as the toxic metabolites involved are not small secondary metabolites but macromolecules. Further research is needed to check whether the macromolecular metabolites of strains 90/2Dm and 92/11-Dm of B. bassiana are produced at physiologically active concentrations during their in vivo growth in L. migratoria and D. maroccanus. If the results of these investigations would be positive, these molecules could be considered as true 'vivotoxins' (Roberts, 1981).

Strain 90/2-Dm was chosen for further toxicological studies because it had also demonstrated a strong insecticidal activity on $D$. maroccanus by per os or contact exposure (Hernández-Crespo \& Santiago-Álvarez, 1997; Jiménez-Medina et al., 1998). Our investigations have demonstrated that the toxic activity detected in culture filtrates of isolate $90 / 2-\mathrm{Dm}$ was not due to low molecular mass metabolites such as cyclopeptides, organic acids or pigments which are known to be produced by B. bassiana and other fungi (Vey et al., 2001). The insecticidal activity was exclusively detected in high molecular weight fractions after dialysis or gel filtration on Sephadex G-25. Furthermore, the precipitation of the toxic metabolites in the crude filtrate of strain $90 / 2-\mathrm{Dm}$ by $90 \%$ saturation of ammonium sulphate, and the reduction of their toxicity by the two thermal treatments, strongly support the assumption that these metabolites were proteins.

Further investigations are presently carried out to try to purify and characterize the macromolecular toxins secreted in vitro by 90/2-Dm. Preliminary results indicate that the biochemical properties of partially purified toxic fractions are different from those of Hirsutellin A, the only high molecular weight compound that has so far been purified to homogeneity (Mazet \& Vey, 1995), and from other proteic macromolecules secreted by strains of $B$. bassiana active against the order Lepidoptera (Vey, unpublished data). The complete purification and characterisation of these active macromolecules will open the opportunity to characterise the cytotoxic effects already detected on cells in living locusts as well as in invertebrate cell cultures, without the interference of other molecules present in the crude sources. Furthermore, by using a specific antiserum, it should be possible to determine if these metabolites are produced in vivo and to establish if they have any role in pathogenesis. It also will allow to extend the studies to other strains and to determine if there is a common feature in the profile of metabolites specifically secreted against locusts by different strains of B. bassiana. Moreover, investigations at the level of the genes encoding for these toxic compounds, as already performed for other virulence factors, namely the PR1 protease of M. anisopliae (St Leger et al., 1992), are a very promising perspective.

Previous studies conducted with the aim to develop a mycoinsecticide for the control of $D$. maroccanus (Hernández-Crespo \& Santiago-Álvarez, 1997; Jiménez-Medina et al., 1998) have focused on the optimisation of the type and quantity of propagules, with practically no consideration given to the quality of inocula. The data reported here provide novel 
information regarding the effect of subculturing on the quality of the conidia produced by this fungus.

Our results demonstrate that passage of B. bassiana 90/2-Dm strain through mycological media and through the host affected its virulence and the toxicity of the macromolecules secreted in its cultures. Attenuation or enhancement of virulence of B. bassiana following repeated subculturing in artificial media (Kawakami, 1960; Schaerffenberg, 1964), and maintenance of virulence (Ferron et al. 1972; Fargues \& Robert, 1983; Brownbridge et al., 2001) have been previously reported. From these studies, it appears that the effect of repeated in vitro subculture of entomopathogenic fungi on their virulence varies depending on species and strains. Our work shows that the type of mycological media has also an influence on the consequences of in vitro subculturing; thus, two passages through SDA caused a decline in virulence of conidia while two passages through MA resulted in conidia more virulent than those from the stock slant cultures. The differences in nutritional composition between SDA and MA might explain the difference in the observed response. It is generally accepted that there is a reduction in the capacity of a fungal isolate to sporulate in nutrient-rich media like SDA (Schaerffenberg, 1964), probably due to an adaptation of the fungus to its saprophytic phase, resulting in a progressive attenuation of its virulence. Strain 90/2-Dm shows the highest production of mycelium in SDA (Quesada-Moraga \& Vey, unpublished data); thus such an adaptation probably occurred during our assays.

The number of passages is a factor that may have an impact on the effect of this kind of treatment. Interestingly, we have observed a significant increase in virulence of strain 90/2Dm after only two passages through MA. Similarly, Schaerffenberg (1964) observed that the maximum virulence of a strain of B. bassiana was reached at the third generation on nutrient medium, it was maintained at the same level up to the 16th generation, and from that point, virulence declined until the 30th generation. As our number of passages was low, further quantitative studies would be useful to document effects of additional in vitro passages beyond two for 90/2-Dm, and other strains of B. bassiana.

B. bassiana is a facultative and opportunistic parasite. Therefore, during culture, the parasitic phase in the life cycle of this entomopathogenic fungus cannot be left out without risk of loss of virulence. For this reason, it is recommended to interrupt artificial culture from time to time by passage through insect hosts (Müller-Kögler, 1966; Aizawa, 1971). Increased virulence after a few passages through insects has also been reported for other entomopathogens (Kawakami, 1960; Hartmann \& Wasti, 1974; Wasti \& Hartmann, 1975; Fargues \& Robert, 1983). However, conflicting results have also been obtained by other authors, as Latch (1976) and Morrow et al. (1989), who did not observe enhancement of virulence of $B$. bassiana after passage through insect hosts.

Our data are in agreement with others reporting a positive effect of passage through the host on virulence, as in our experimental conditions strain 90/2-Dm exhibited the highest level of virulence after two passages through L. migratoria. As this strain was originally isolated from $D$. maroccanus, such results suggest that passage through $L$. migratoria might also have led to an adaptation to this alternative host.

The passages through mycological media and through the host also affected the toxicity of the metabolites produced in vitro by isolate $90 / 2-\mathrm{Dm}$ of $B$. bassiana. This is the first study to establish the effect of the in vitro subculturing of entomogenous fungi on this metabolic process. No significant differences in toxicity were observed among the four types of crude filtrates containing all types of fungal molecules, whereas the insecticidal activity of adialysates was clearly determined by the type of conidia used for the inoculation of cultures. The differences in toxicity between crude filtrates and adialysates cannot be attributed to differences in total protein concentration as similar quantities were injected. The disparity between the two types of sources of fungal metabolites probably reflects differences in their chemical composition. As adialysates represent a first level of increased purity and as risk of interference between macromolecules and low molecular weight 
components of the filtrate had disappeared as a consequence of dialysis, the bioassays performed with adialysates were more useful to reveal the changes which may occur in the biosynthesis of macromolecular toxic metabolites.

Our results indicate that the B. bassiana $90 / 2-\mathrm{Dm}$ strain is stable enough to be submitted to a limited number of repeated transfers on MA, as could occur during the mass-production process, without any adverse effects on its virulence and ability to produce toxic macromolecular metabolites. This stability is another favourable characteristic of this strain, in addition to its virulence and toxicogenic activity; thus we consider the 90/2-Dm strain of $B$. bassiana as a good candidate for improving its performance and for developing a marketable agent for the control of D. maroccanus.

\section{ACKNOWLEDGEMENTS}

This research was supported by the European Commission Marie Curie Individual PostDoctoral Fellowship Contract no. PMFCT-2000-00621. The authors would like to thank Ms. Karine Moreau, Mrs. Anna-Marie Travier and Mr. Jean-Lue Meynier for their technical assistance. They also thank Dr. Martin Drucker, Comparative Pathology Research Station (INRA), for critically reviewing the manuscript.

\section{REFERENCES}

Аввотт, W.S (1925) A method of computing the effectiveness of an insecticide. Journal of Economic Entomology 18, 265-267.

AızawA, K. (1971) Strain improvement and preservation of virulence, in Microbial Control of Insects and Mites (Burges, H.D. \& Hussey, N.W., Eds.). Academic Press, New York, pp. 666-668.

Amiri-Besheli, B., Khambay, B., Cameron, S., Deadman, M.L. \& Butt, T.M. (2000) Inter- and intraspecific variation in destruxin production by insect pathogenic pathogenic Metarhizium spp., and its significance to pathogenesis. Mycological Research 104, 447-452.

Anonymous (1996) Statistic for Windows. Analytical Software.

BRADFORD, M.M. (1976) A rapid and sensitive method for the quantitation of microgram quantities of protein utilizing the principle of protein-dye binding. Annals of Biochemistry 72, 248-254.

Brownbridge, M., Costa, S. \& JAROnSki, S.T. (2001) Effects of in vitro passage of Beauveria bassiana on virulence to Bemisia argentifolii. Journal of Invertebrate Pathology 77, 280-283.

Butt, T.M., JACKSON, C. \& MAGAN, N. (2001) Fungal biocontrol agents: progress, problems and potential, in Fungi as Biocontrol Agents Progress, Problems and Potential (Butt, T.M., JACKson, C.W. \& MaGAN, N., Eds.). CABI Publishing, pp. 219-238.

FArgues, J.F. \& Robert, P.H. (1983) Effects of passaging through scarabaeid host on virulence and host specificity of two strains of the entomopathogenic hyphomycete Metarhizium anisopliae. Canadian Journal of Microbiology 29, 576-583.

Ferron, P., Deotte, A. \& Marshal, M. (1972) Stabilité de la virulence d'une souche do Beauveria tenella (Decacr.) Siemaszko (Fungi Imperfecti) pour les larves du coleoptere, Melolontha Melolontha. L.C.R Academie Sciences Paris 275, 2977-2979.

Hartmann, G.C. \& Wasti, S.S. (1974) Infection of the Gypsy moth, Porthetria dispar (L.) with the entomogenous fungus, Conidiobolus coronatus (Cost) Batko. Entomophaga 19, 353-360.

Hernández-Crespo, P. \& Santiago-Alvarez, C. (1997) Entomopathogenic fungi associated with natural populations of the Moroccan locust Dociostaurus maroccanus (Thunberg) (Orthoptera: Gomphocerinae) and other acridoidea in Spain. Biocontrol Science and Technology 7, 357-363.

Jiménez-Medina, J., Quesada-Moraga, E., Aldebis, H.K. \& Santiago-Álvarez, C. (1996) Evaluation of fungi isolated from Dociostaurus maroccanus (Thunberg) at the breeding area of La Serena (Badajoz,Spain) for the control of its populations, in 29th Annual Meeting of The Society for Invertebrate Pathology and IIIrd International Colloquium on Bacillus thuringiensis. Córdoba, Spain, 1-6 September., p. 40.

Jiménez-Medina, J., Aldebis, H.K. \& Santiago-Alvarez, C. (1998) Valoración insecticida de diversos aislados de hongos hifomicetos para el control de la langosta mediterránea, Dociostaurus maroccanus (Thunberg). Boletin Sanidad Vegetal Plagas 24, 867-872.

Kachatourians, G.G. (1991) Physiological and genetics of entomopathogenic fungi, in Handbook of Applied Mycology (Arora, D.K., Ajello, L. \& Mulkerji, K.G., Eds.). Marcel Dekker, New York, pp. 613663. 
KawAKAMI, K. (1960) On the changes of characteristics of the silkworm muscardines through successive cultures. Bulletin Sericulture Experimental Station Japan 16, 83-99.

Kershaw, M.J., Moorhouse, E.R., Bateman, R., Reynolds, S.E. \& Charnley, A.K. (1999) The role of destruxins in the pathogenicity of Metarhizium anisopliae for three species of insects. Journal of Invertebrate Pathology 74, 213-223.

Latch, G.C.M. (1976) Studies on the susceptibility of Oryctes rhinoceros to some entomogenous fungi. Entomophaga 21, 31-38.

Latchininsky, A.V. \& Launois-Luong, M.H. (1992) Le cricket marocain, Dociostaurus maroccanus (Thunberg, 1815) dans la partie orientale de son aire de distribution. Etude monographique à L'ex-URSS et aux pays proches. CIRAD-GERDAT-PRIFAS: Montpellier/VIZR: Saint-Pétersbourg, $270 \mathrm{pp}$.

Lomer, C.J., Bateman, R.P., Johnson, D.L., Langewald, J. \& Thomas, M. (2001) Biological control of locusts and grasshoppers. Annual Review of Entomology 46, 667-702.

Mason, P.G. \& ERLANDSON, M.A. (1994) The potential of biological control for management of grasshoppers (Orthoptera, Acrididae) in Canada. Canadian Entomologist 126, 1459-1491.

MAzet, L. \& VeY, A. (1995) Hirsutellin A, a toxic protein produced in vitro by Hirsutella thompsonii. Microbiology 141, 1343-1348.

Mazet, L., Hung, S.Y. \& Boucias, D.G. (1994) Detection of toxic metabolites in the hemolymph of Beauveria bassiana infected Spodoptera exigua larvae. Experientia 50, 142-147.

Morrow, B.J., Boucias, D.G. \& Heath, M.A. (1989) Loss of virulence in an isolate of an entomopathogenic fungus, Nomuraea rileyi, after serial in vitro passage. Journal of Economic Entomology 82, 404-407.

MülLER-Kögler, E. (1966) On mass cultivation, determination of effectiveness, and standardization of insect pathogenic fungi, in Insect Pathology and Microbial Control. Proceedings of the International Colloquium of Insect Pathology and Microbial Control. Wageningen, The Netherlands. 5-10 September, pp. 339-353.

Prior, C. \& Greathead, D.J. (1989) Biological control of locust: the potential for the explotation of pathogens. FAO Plant Protection Bulletin 37, 37-48.

Quesada-Moraga, E. \& Santiago-Alvarez, C. (2001) Histopathological effects of Bacillus thuringiensis on the midgut of the mediterranean locust Dociostaurus maroccanus. Journal of Invertebrate Pathology 78, $183-186$.

RoberTs, D.W. (1981) Toxins of entomopathogenic fungi, in Microbial Control of Pests and Plant Disease (Burges, H.D., Ed.). Academic Press, New York, pp. 441-464.

SchaerfFenBerg, B. (1964) Biological and environmental conditions for the development of mycoses caused by Beauveria and Metarhizium. Journal of insect Pathology 6, 8-20.

SPSS INC. (1997) SPSS 8.0 for Windows. SPSS Inc. Headquarters, $233 \mathrm{~S}$. Wacker Drive, 11th floor, Chicago. IL 60606, USA.

St Leger, R.S. \& SCReen, S. (2001) Prospects for strain improvement of fungal pathogens of insects and weeds, in Fungi as Biocontrol Agents Progress, Problems and Potential (BUTT, T.M., JACKson, C.W. \& MAGAN, N, Eds.). CABI publishing, pp. 219-238.

St Leger, R.J., Frank, D.C., Roberts, D.W. \& Staples, R.C. (1992) Molecular cloning and regulatory analysis of the cuticle-degrading protease structural gene from the entomopathogenic fungus Metarhizium anisopliae. European Journal of Biochemistry 204, 991-1001.

St Leger, R.J., Joshi, L., BidochKa, M.J. \& Roberts, D.W. (1996) Construction of an improved mycoinsecticide over-expresing a toxic protease. Proceedings of the National Academy of Sciences USA 93, 6349-6354.

Vázques-Lesmes, R \& Santiago-Álvarez, C. (1993) La langosta en el Reino de Córdoba. Publicacioncs del Monte de Piedad y Caja de Ahorros de Córdoba, Colección Mayor, Córdoba; 300 pp.

Vey, A., Hoagland, R. \& Butt, T.M. (2001) Toxic metabolites of fungal biocontrol agents, in Fungi as Biocontrol Agents Progress, Problems and Potential (Butt, T.M., Jackson, C.W. \& Magan, N, Eds.). CABI Publishing, pp. 311-346.

Wasti, S.S. \& Hartmann, G.C. (1975) Experimental parasitization of larvae of the Gypsy moth, Porthetria dispar (L.) with the entomogenous fungus, Beauveria bassiana (Balsamo) Vuill. Parasitology 70, 341346.

Wraight, S.P., Jackson, M.A. \& Kock, S.L. (2001) Production, stabilization and formulation of fungal biocontrol agents, in Fungi as Biocontrol Agents Progress, Problems and Potential (ButT, T.M., JACKsON, C.W. \& Magan, N., Eds.). CABI Publishing, pp. 253-288. 


\section{Author Query Sheet}

\begin{tabular}{|l|l|l|l|}
\hline $\begin{array}{l}\text { Journal } \\
\text { Acronym }\end{array}$ & CBST & Volume/Issue & \\
\hline $\begin{array}{l}\text { Author } \\
\text { name }\end{array}$ & E. QUESADA-MORAGA & $\begin{array}{l}\text { Mss No. (if } \\
\text { applicable) }\end{array}$ & $\mathbf{0 1 2 - 0 2}$ \\
\hline
\end{tabular}

AUTHOR: The following queries have arisen during the editing of your manuscript. Please answer the queries by marking necessary corrections at the appropriate positions on the PROOFS. Do not answer the queries on the query sheet itself. Please also return a copy of the query sheet with your corrected proofs

\begin{tabular}{|c|l|}
\hline $\begin{array}{c}\text { QUERY } \\
\text { NO. }\end{array}$ & \multicolumn{1}{c|}{ QUERY DETAILS } \\
\hline Q1 & $\begin{array}{l}\text { Text states Khachatourians but reference list states Kachatourians - which spelling is } \\
\text { correct? }\end{array}$ \\
\hline
\end{tabular}

